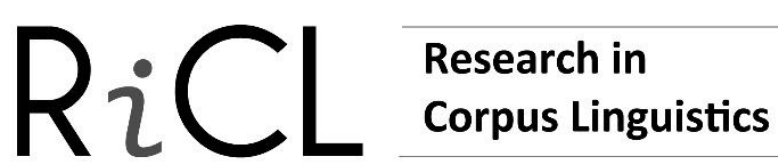

\section{Brazilian cultural markers in translation: A model for a corpus-based glossary}

\author{
Rozane Rebechi ${ }^{\mathrm{a}}$ - Stella Tagnin ${ }^{\mathrm{b}}$ \\ Universidade Federal do Rio Grande do Sul ${ }^{\text {a }}$ Brazil \\ Universidade de São Paulob / Brazil
}

\begin{abstract}
Translations in the Brazilian culinary domain are often characterized by the use of inaccurate equivalents, a lack of fluency, and adaptations that lead to a mischaracterization of cultural references. This is due to a lack of reliable reference materials in that area which usually only offer a translation, without any context or explanation. To address these issues, this paper draws upon a corpus-informed methodology to devise a three-level entry - term/equivalent, appositive explanation and encyclopedic information - for Brazilian cooking terms in a Portuguese-English glossary aimed at translators and writers of culinary texts.
\end{abstract}

Keywords - Brazilian cooking terminology; cultural markers; corpus linguistics

\section{INTRODUCTION}

Why should a word in a recipe be less important than a word in a novel? One can lead to physical indigestion, the other to mental. (Barnes 2003: 7)

As well as being one of the fundamental elements of human existence, food is a distinctive cultural constituent of every nation. Despite being a popular topic, it is rarely regarded as a theme worthy of serious academic study (Brien 2007). Fortunately, this picture has changed over the past few years, with a considerable amount of literature on the culinary arts being recently published. Academic research has resulted in monographs, book chapters and papers (see, for example, Gerhardt et al. 2013; Jurafsky 2014; Temmerman and Dubois 2017; Tigner and Carruth 2018), and the connection between food and translation has given rise to scholarly events, such as the International Conference on Food and Culture in Translation (FaCT), held in Italy in 2014 and 2016. Nevertheless, as a result of the long neglect of the culinary domain at academic level (see Capatti and Montanari 1999), few reference materials have been published in the area, at least as far as the Portuguese-English language pair is concerned, and this paucity has had negative consequences for translation studies.

Research in Corpus Linguistics 8: 65-85 (2020). ISSN 2243-4712. <https://ricl.aelinco.es>

Asociación Española de Lingüística de Corpus (AELINCO) DOI 10.32714/ricl.08.01.05 
Food items "wander around the globe" (Gerhardt 2013: 17) in such a way that the cuisine of any given nation can be accessed by anyone and anywhere. Brazilian cooking is no exception. Driven by both international sports events held in the country -2014 FIFA World Cup and 2016 Olympic Games- and the worldwide renown of chefs who privilege local products, Brazilian cooking has received special attention from foreign audiences, judging by the number of Brazilian cookbooks published in English. ${ }^{1}$ Unfortunately, these publications also reveal misunderstandings regarding Brazilian cuisine.

A melting pot basically influenced by Portuguese colonizers, Native Indians, and African slaves, typical Brazilian cooking is very rich in native, endemic and exotic ingredients and local preparations. Nevertheless, it is commonly reduced to a few items in general cooking dictionaries and bilingual glossaries, which often fail to define and/or translate them accurately and consistently. Through an examination of the few existing bilingual cookery dictionaries and glossaries, in addition to general monolingual and bilingual dictionaries available on the Brazilian market, Rebechi (2015a, 2015b) demonstrated that most of them are ineffective in providing equivalents and/or appropriate definitions for many typical Brazilian products. Contextualized examples, which could enhance comprehension, are also absent. As a consequence, texts related to Brazilian cooking often display mistranslations, inaccurate definitions of terms and substitution of ingredients, generating products and dishes that are not representative of our national cuisine. We believe that these problems might have been easily addressed if reliable lexicographical references were available.

One of the greatest challenges of compiling a reference material in the area is ensuring that the distinctive cultural characteristics of Brazilian cooking are maintained. Thus, we believe that a representative reference work aimed at translators in the area should not only provide equivalents for terms -whenever they have an equivalent- but also offer other key information which could be used in the translation. The main purpose of this article is to offer a model of a glossary entry which has been customized specifically for Brazilian culinary items, based on a corpus of authentic texts containing cooking recipes. The entries are meant to provide translators and writers of culinary texts

\footnotetext{
${ }^{1}$ The combination of the search words Brazilian and cooking resulted in 240 titles available on the Amazon online store. (9 January, 2020.)
} 
with terms -along with their English equivalents-, appositive explanations, and encyclopedic information about typical Brazilian food items. Examples of use and phraseological units are included as additional data. To achieve our goal, we rely on Corpus Linguistics (CL) procedures which allow for an analysis of the term in context (see Pearson 1998).

\section{CULTURAL MARKERS IN TRANSLATION}

According to Newmark (1988: 94), culture refers to "the way of life and its manifestations that are peculiar to a community that uses a particular language and its means of expression." He emphasizes that words which are characteristic of a certain culture (what we call cultural markers) will pose problems to the translator, unless source and target languages overlap. Cultural markers are here understood as textual, lexical, and discursive elements relating to specific cultures (Zavaglia et al. 2011), which can be found in any text type, either general, literary or specialized. Also called identity markers, they refer to various elements used to display preferences towards other cultures. As an important expression of a culture, food-related items demand a number of decisions when they are translated from one culture to another (Newmark 1988).

Still according to Newmark (1988: 97), "[f]ood is for many the most sensitive and important expression of national culture." Hence, when shared with other cultures, food items are subject to a number of procedures, depending on the purpose of the translation. Regarding the translation of Brazilian cultural markers, we observe recurrent choices for functional equivalents (see Nord 2001, 2012). By rendering cultural words with culturefree words, the translator or writer neutralizes or generalizes a term (Newmark 1988). This procedure may result in a successful strategy regarding the translation of recipes when the aim is to guide a cook toward the appropriate preparation of a dish. For example, replacing buttermilk with a mixture of yogurt and milk will not affect the final result dramatically. On the other hand, using a different kind of bean, instead of the feijão fradinho 'black-eyed peas' to prepare acarajé (spoonful-sized fritter made from puréed black-eyed peas seasoned with salt and onion, deep-fried in dendê oil $)^{2}$ will certainly render a quite different type of bean fritter. Besides, what motivates a foreigner to choose

\footnotetext{
${ }^{2}$ Dendê oil is a thick, dense, reddish oil with a delectable flavor and aroma used as an ingredient in Bahian dishes.
} 
a Brazilian recipe is probably the exoticism of our typical foods. Similarly, when Brazil's national drink cachaça is rendered as 'crude/sugarcane brandy', 'spirit(s)' or '(sugarcane) rum', it loses its culture-specific character and fails to convey a sense of foreignness (Rebechi 2012). Although 'cultural filtering' (Chesterman 1997) could simplify the reader's task by naturalizing cultural terms, it would at the same time frustrate the expectations to taste a foreign flavor.

Mistranslation is also disturbing and abundant. One example will suffice. In a leaflet published by Brazil's Ministry of Culture (Ministério da Cultura 2014), one of the ingredients of quentão, a drink served during the June festivals of Brazil and prepared with cachaça, sugar, and spices, was translated as 'harpsichord', instead of 'clove'. The confusion is probably due to the polysemy of the word cravo in Portuguese, and to the fact that general language dictionaries usually provide a list of decontextualized equivalents, as is the case of the entry for the word cravo, translated in the Webster's Portuguese English Dictionary (2007) as 'horseshoe nail; spike; corn, callus; comedo (blackhead); spinet, harpsichord, clavichord; carnation, clove-pink' (s.v. cravo (m)). As we can see, the dictionary does not provide definitions or examples which could help the researcher to distinguish among the different senses of the equivalents listed, including the musical instrument, mistakenly chosen by the translator. To make things worse, culinary translation is usually relegated to laypersons, since it is traditionally considered an easy task (Teixeira 2004). Although some may believe that recipes can be easily translated, they are now recognized as texts which can reveal important aspects of the source culture, thus demanding more than just terminological expertise and a search for equivalence in order to be appropriately translated. In other words, cooking recipes may demand that the translator be somehow acquainted with the source culture.

Another strategy frequently used in translating Brazilian food terms into English regards the titles of recipes. Based on the traditional narrative framework proposed by Labov (1972), Cotter (1997) compares the title of a recipe to an abstract, which means that it provides the reader with an overview of what follows. This is true for informative or descriptive titles, such as bolo de coco 'coconut cake', arroz com pequi 'rice with pequi' and sopa de legumes 'vegetable soup'. However, Brazilian recipes may often have idiomatic, non-compositional titles, which cannot be translated literally, as this would compromise communication. Literal translations such as angel's double chin, brigadier and little peasant girl, only to mention a few found in the English subcorpus (detailed in 
4.1), would certainly create a quite different image in the foreign reader's mind than papo de anjo, brigadeiro and caipirinha do for Brazilians.

As should be clear by now, we believe that identifying and rendering cultural markers appropriately in the target language should be a major concern of translators so as to maintain the specificities of the culture represented in the text. Specialized reference works can help to achieve this goal as they are meant to be a more focused source of terminology retrieval for specific areas, besides contributing with terminology consistency and conventionality.

\section{BRAZILIAN PORTUGUESE-ENGLISH CULINARY REFERENCE WORKS}

Translation studies are frequently divided into two large -and supposedly differingcategories: (i) literary and (ii) technical and scientific. After decades in which the former dominated scholarly attention, the late twentieth and early twenty-first centuries have witnessed an increasing interest in the so-called specialized texts. Actually, a clear-cut distinction between general, literary or specialized texts is questionable. Mayoral Asensio (2007) claims that there is no boundary distinguishing general from specialized language since any act of communication might contain, albeit at different levels, elements of general and specialized languages. Dona Flor e seus Dois Maridos (Amado 1966) is a good example of hybridity. ${ }^{3}$ Dona Flor, the main character of the novel, is a culinary instructor in Salvador, in the state of Bahia and, hence, traditional Bahian dishes, such as abará (puréed black-eyed peas seasoned with salt, onion, dried shrimp and dendê oil, wrapped in banana fronds and steamed) and acaraje are frequently mentioned in the novel. Nevertheless, such cultural markers have constantly lost their identity in translation as well as in texts originally written in English. We believe that one of the reasons for this problem is directly linked to the reference works available.

We looked into some of the (few) Portuguese-English reference works addressing cookery in order to analyze the extent to which they would help translators and writers. The works we examined were the Dicionário de Termos Gastronômicos em 6 Idiomas (Saldanha 2015), Glossário de Gastronomia: Português-Inglês/Inglês-Português (Klie 2006), Vocabulário para Culinária: Inglês-Português (Teixeira and Tagnin 2008) and

\footnotetext{
${ }^{3}$ See Azenha (1999: 49) for a discussion of hybrid forms.
} 
Dicionário Gastronômico: Português-Espanhol-Inglês-Alemão-Francês-Italiano (Carli and Klotz 2007). A summary of the content of the aforementioned works is shown in Table 1 below.

\begin{tabular}{|c|c|c|c|c|c|}
\hline Title & Direction & Equivalent & Phraseology & Definition & Example \\
\hline $\begin{array}{l}\text { Dicionário de } \\
\text { Termos } \\
\text { Gastronômicos }\end{array}$ & $\begin{array}{c}\text { Portuguese- } \\
\text { English/Spanish/ } \\
\text { French/Italian/German }\end{array}$ & Yes & No & No & No \\
\hline $\begin{array}{l}\text { Glossário de } \\
\text { Gastronomia }\end{array}$ & $\begin{array}{l}\text { Portuguese-English } \\
\text { English-Portuguese }\end{array}$ & Yes & No & No & No \\
\hline $\begin{array}{l}\text { Vocabulário Para } \\
\text { Culinária: Inglês- } \\
\text { Português }\end{array}$ & English-Portuguese & Yes & Yes & Yes & Yes \\
\hline $\begin{array}{l}\text { Dicionário } \\
\text { Gastronômico }\end{array}$ & $\begin{array}{c}\text { Portuguese- } \\
\text { Spanish/English/ } \\
\text { German/French/Italian }\end{array}$ & Yes & No & No & No \\
\hline
\end{tabular}

Table 1: Elements of some Portuguese-English reference works

Except for Teixeira and Tagnin (2008), who drew upon authentic recipes and analyzed them semi-automatically to offer not only equivalents for cooking terms, but also collocations and explanations (for example, distinguishing between similar ingredients), the reference works mentioned would not help translators with the use of terms, since no definitions or examples are offered. In order to help fill this gap, we propose a three-level entry consisting of term/equivalent, appositive explanation and encyclopedic information for our Portuguese-English Glossary of Brazilian Cooking.

\section{CORPUS LINGUISTICS AND TERM EXTRACTION}

Defined by McEnery and Hardie (2012: 1) as an "area which focuses upon a set of procedures, or methods, for studying language," CL encompasses the compilation and exploration of sets of texts (corpora) collected under well-defined criteria and processed by electronic tools (Bowker and Pearson 2002). A methodology based on CL relies on research in authentic texts, analysis of large amounts of data, automatic retrieval of terms, collocations and recurring combinations (clusters). In addition, it facilitates the search for equivalents and definitions.

Contrary to popular belief that anyone who can cook can translate recipes (see Teixeira 2004), these are highly specialized texts, rich in terminology, which require specialized translator training. As our main purpose is to retrieve terms which are typical of Brazilian cooking, as well as possible equivalents, definitions and authentic examples in English, we have compiled a corpus of Brazilian recipes in Portuguese and in English. 


\subsection{Cooking recipes}

Like any specialized text, recipes contain lexical and syntactic specificities, characteristic terminology -cup, spoon, dice- and combinations of words (phraseological units) -bring to a boil, add gradually, stirring constantly-which immediately evoke the genre (see Bubel and Spitz 2013). Moreover, the instructions normally conveyed by verbs in the imperative -at least in English and in Portuguese- allow us to define recipes as instructional texts. Due to their highly specialized content, cookbooks were chosen for our study corpus. We compiled a comparable corpus, with recipes originally written in Portuguese and in English, and a parallel corpus, with recipes originally written in Portuguese and their translations into English.

In order to identify what characterizes Brazilian cooking, we relied on eleven cookbooks published in the country as of 1990, in order to privilege what is still part of the population's eating habits. The cookbooks chosen allegedly comprise national or regional recipes - their titles include the words Brasil, brasileiro(a), or the name of a state or region. ${ }^{4}$ All the books feature an introductory text in which the authors discuss different aspects of Brazilian culture and cuisine. We also collected metatexts, in the form of prefaces and introductions, which are frequently included in the cookbooks to explain why the authors decided to write such a work, how the recipes were chosen, what characterizes Brazilian cooking, besides explanations about what is typical of each region. These texts proved to be a rich source of term definition extraction, as will be demonstrated in Section 5.2.

The English counterpart of the comparable corpus, that is, recipes originally written in English, comprises eleven cookbooks published in the United States in the same period, whose titles contain the words Brazil or Brazilian. Despite the numerous recipes available online, we privileged printed cookbooks as a way to track information considered important to this research, such as authorship, location of publisher, publication date, etc. For the comparable corpus, the cookbooks were required to be originally written in Brazilian Portuguese and in North-American English. This compilation criterion obviously restricted the corpus size, as digitizing the books demanded time. According to the introductory texts, which were manually analyzed, the cookbooks that comprise the study corpus are not addressed to professional cooks. In what concerns the English

\footnotetext{
${ }^{4}$ See Rebechi (2015b) for a complete list of the books which the study corpus comprises.
} 
subcorpus, we observed that the authors provide considerably more information about the reason why they decided to compile a cookbook with Brazilian recipes. In general, they claim to have lived in the country to work or to accompany the spouse.

As six of the eleven cookbooks in Portuguese were translated into English, our research also relies on a parallel corpus. This material was digitized to be automatically processed by WordSmith Tools (Scott 2012). Tables 2 and 3 summarize the content of our study corpora.

\begin{tabular}{lcc}
\hline \hline & Portuguese & English \\
\hline Introductory texts & 194,713 & 148,136 \\
Recipes & 234,704 & 282,977 \\
Total tokens & $\mathbf{4 2 9 , 4 1 7}$ & $\mathbf{4 3 1 , 1 1 3}$ \\
\hline \hline
\end{tabular}

Table 2: Comparable corpus

\begin{tabular}{lcc}
\hline \hline & Portuguese & English \\
\hline Introductory texts & 51,806 & 58,468 \\
Recipes & 109,221 & 107,197 \\
Total tokens & $\mathbf{1 6 1 , 0 2 7}$ & $\mathbf{1 6 5 , 6 6 5}$ \\
\hline \hline
\end{tabular}

Table 3: Parallel corpus

\subsection{Terminology and phraseology retrieval}

In order to identify Brazilian cultural markers related to cooking, and to propose appropriate equivalents, explanations, and encyclopedic information, complemented by examples of use and phraseological units, we started with a quantitative approach, resorting mainly to the keywords provided by WordSmith Tools, which was complemented by a qualitative approach, that is, an analysis of the concordance lines in which these keywords occurred.

Although in general keywords are extracted by comparing a reference corpus of general language with a study corpus, in this study our reference corpus was composed of general cooking recipes in Portuguese, so that the comparison revealed terms which are specific to Brazilian cooking, not general cooking. The reference corpus with approximately one million words (Teixeira 2008) consists of home cooking recipes extracted with an offline browser from websites which do not distinguish their recipes according to their places of origin. As previously stated, the study corpus consists of 22 printed cookbooks which had to be digitalized, and this time-consuming task could not be repeated in the construction of the reference corpus. Therefore, we used a corpus from 
a different source, but which is made up of the same genre, that is, cooking recipes.

The Portuguese comparable subcorpus revealed a list of single and compound keywords, that is, words which appear statistically more often in the texts analyzed than in the reference corpus. We then proceeded to retrieve key-keywords, or words which are key in two or more texts or corpora (Scott and Tribble 2006). In order to extract terms related to Brazilian cooking, we only considered keywords which recurred in a minimum of two books. This setting was established as a way of discarding elements which appeared systematically in just one cookbook, which could indicate idiosyncrasy.

From the Portuguese subcorpus with a total of eleven texts, we selected one-word and multi-word terms, which constitute the glossary headwords. Table 4 shows the first 20 terms in decreasing order of keyness. When an English equivalent or translation was identified in the comparable or parallel corpus, it is provided in brackets (detailed information about the identification of equivalents is presented in Section 5.1). Singular and plural occurrences were manually lemmatized.

\begin{tabular}{llccc}
\hline \hline N & Keyword & Texts & \% & Overall Freq. \\
\hline 1 & farinha de mandioca 'manioc flour' & 11 & 100 & 318 \\
2 & mandioca 'manioc/cassava' & 11 & 100 & 484 \\
3 & charque 'beef jerky' & 10 & 90.91 & 111 \\
4 & coco(s) 'coconut(s)' & 10 & 90.91 & $682(+49)$ \\
5 & feijão 'bean' & 10 & 90.91 & 283 \\
6 & leite de coco 'coconut milk' & 10 & 90.91 & 370 \\
7 & milho 'corn' & 10 & 90.91 & 288 \\
8 & arroz 'rice' & 9 & 81.82 & 524 \\
9 & doce 'sweet' & 9 & 81.82 & 191 \\
10 & farofa & 9 & 81.82 & 152 \\
11 & goma '(manioc) starch' & 9 & 81.82 & 86 \\
12 & pirão & 9 & 81.82 & 124 \\
13 & porco 'pork' & 9 & 81.82 & 193 \\
14 & arroz branco 'white rice' & 8 & 72.73 & 98 \\
15 & caranguejo(s) 'crab(s)' & 8 & 72.73 & $92(+16)$ \\
16 & carne-seca 'dried beef' & 8 & 72.73 & 102 \\
17 & coco ralado 'grated coconut' & 8 & 72.73 & 97 \\
18 & coentro 'cilantro/coriander' & 8 & 72.73 & 334 \\
19 & espigas '(corn) cobs' & 8 & 72.73 & 54 \\
20 & jambu & 8 & 72.73 & 94 \\
\hline \hline
\end{tabular}

Table 4: First 20 one-word and multi-word Portuguese key-keywords

It must be said that, although processing a list of key-keywords greatly facilitated the identification of salient terms or candidates as entries in the glossary, a careful look at 
their contexts, mainly enabled by the analysis of concordance lines, determined the final selection. Let us take the key-keyword codorna 'quail' as an example. This poultry could be an ingredient in many dishes, but the analysis of the concordance lines demonstrated that in the Portuguese subcorpus this keyword is part of the cluster ovo(s) de codorna 'quail egg(s)' in nine out of its ten occurrences. Therefore, the term which refers to the poultry, rather than the eggs, was discarded. Also, strings of words with incomplete meaning, for example, de codorna, farinha de, etc. were equally ignored. This way, Brazilian cooking terms were manually selected from the keyword lists in Portuguese to compose the glossary entries. Equivalents, explanatory texts, examples, encyclopedic information, and phraseological units were retrieved from the texts in English. The microstructure of the Portuguese-English Glossary of Brazilian Cooking is explained in detail in the next section.

\section{GLOSSARY ENTRIES: MiCROSTRUCTURE}

To build our entries, we used TshwaneLex (Joffe and de Schryver 2004), a software suite for compiling dictionaries. In addition to the basic three-level categories (equivalent, appositive explanation, and encyclopedic information), we customized the tool so that fields for word class, scientific name (to be used for Brazilian flora and fauna terms), example(s), phraseological unit(s), reference(s), and image(s) were also available. The elements which are judged to be most relevant to the translator and writer of culinary texts are detailed below.

\subsection{Translation equivalent}

In terminology, two terms are considered equivalent when they possess full correspondence of meaning and use within the same area of expertise. However, full correspondence is not a very common phenomenon. Often, a given term in the target language will only partly cover the meaning of the term in the source language (Dubuc 1999). When dealing with an area which is rich in cultural references like cooking, the non-equivalence problem becomes even more evident. However, the translator or writer needs to render concepts from one language to the other as appropriately as possible.

As Newmark (1988: 45) points out, "[t]he central problem of translating has always been whether to translate literally or freely." As previously discussed, it is common sense 
now that translation procedures should take into account the function of the translated text for its own readership. In view of the numerous national food items now available all over the world, it seems that people would look for ethnic food driven by their interest in what is characteristic of a foreign culture. Bearing this in mind, we aim to provide the reader with translation equivalents which maintain the foreignness of culture-bound elements. For the compilation of the Glossary of Brazilian Cooking, different equivalence strategies were used, based on Newmark's (1988) translation methods.

\subsubsection{Transference}

Many Brazilian cooking terms are derived from native Indian and African words. As such, they may sound foreign even to Brazilians, who do not necessarily know their primary meaning. One example is tapioca, from Tupi tipioca, which means 'clot'. The analysis of this keyword in context showed that it is used mainly to refer to (i) a dish (see Figure 1) and (ii) a type of flour derived from manioc, which is the base for this dish. The analysis of the English subcorpus revealed that, as a dish, the term is usually transferred to the target text; as an ingredient, a number of equivalents were used: tapioca, tapioca flour, tapioca starch, manioc flour, manioc starch, and cassava flour. Due to space constraints, we cannot discuss the adequacy of each translation. For the glossary, we opted for keeping the word in its original form, thus allowing some foreignness to shine through the text, as shown in Figure 1.

\footnotetext{
tapioca' (noun) tapioca A crepe-like dish prepared with moist manioc starch, eaten plain, with butter or filled with savory or sweet ingredients. //Ex.: With the heat, the mixture will cohere into a thick pancake. Lower the heat and flip the pancake to cook the other side. [Brasil: Gastronomia, Cultura e Turismo]ll A genuinely Brazilian delicacy, tapioca was originally a food of the natives and became very popular in the North and Northeast, where it usually replaces bread during breakfast. Very versatile, the basic recipe (the manioc starch is moistened, sieved and sprinkled onto a hot pan so that the starchy grains fuse into a flatbread) is folded or rolled and, due to its almost neutral flavor, may receive sweet or savory fillings such as grated coconut, curd cheese, shredded beef jerky, banana etc. Besides being fat-, gluten- and sugar-free, tapioca is very nutritious. Nowadays, it is possible to find ready-to-use moist manioc starch for tapioca at supermarkets. See also carne-de-sol, queijo-de-coalho, polvilho Also known as beiju Compare with $\underline{\text { tapioca }}^{2}$
}

Figure 1: Entry tapioca with borrowed equivalent 


\subsubsection{Literal translation}

The list of key-keywords in English revealed highly frequent items, such as coconut milk, shrimp and coriander, which can literally translate as leite de coco, camarão and coentro. Even native items, such as castanha de caju and castanha-do-pará, have been frequently rendered respectively as cashew nut (or simply cashews) and Brazil nut, words with high keyness in the English subcorpus. Figure 2 shows the entry for leite de coco, with the equivalent highlighted.

leite de coco (noun) coconut milkJuice obtained from squeezing grated coconut and used in the preparation of sweet and savory dishes, especially in Bahian cooking. //Ex.: Fold in the grated manioc root and gradually add the milk and coconut milk. [Brazil: a Cook's Tour]ll Easily found canned or bottled, coconut milk can also be made at home by squeezing grated coconut milk to obtain thicker or thinner consistency. Mostly used in the northeastern cuisine for the preparation of fish and seafood stews such as moqueca and bobó, it is also used in desserts such as manjar and baba de moça./IPhrase. add the coconut milk; thick coconut milk; (fresh or canned) unsweetened coconut milk; thin coconut milk See also baba de moça, manjar, moqueca, bobó

Figure 2: Entry leite de coco with literal equivalent

\subsubsection{Functional equivalent}

Even when two languages and cultures do possess similar concepts and, hence, dictionary equivalents, literal translation may not be adequate in all situations. Newmark (1988) explains that choosing a functional equivalent is a common procedure usually applied to cultural words by rendering them with culture-free words, combined or not with transference. A close examination of the keywords in both languages shows that the recipes in North-American English tend to be more technical than the ones in Portuguese. An example is the term cortador de legumes 'vegetable slicer', frequently rendered in the English subcorpus as mandoline, which does have a prima facie equivalent in Portuguese, namely mandolina. However, this term seems to be restricted to professional cooks. The Portuguese subcorpus has no occurrence of mandolina, while the term is described in the book Chef Profissional (2011) as an important kitchen utensil.

Considering that the degree of technicity may vary from one language and culture to another, the translator and writer must be very careful about using literal translation to render culture-bound elements. After all, when a term is translated literally, it is often possible to confound the concept referred to with a similar one. Let us take as an example farinha de milho, a type of coarse meal made from corn and used basically in the 
preparation of two recipes: cuscuz and farofa. If literally translated as corn meal, cornmeal or corn flour, as identified in the English subcorpus, it might be confused with fubá, the main ingredient used in the preparation of polenta, for instance, as if they were interchangeable in recipes. And the reference works available are not helpful in avoiding misunderstandings either. ${ }^{5}$

A search in the parallel corpus revealed the translators' strategy of adding a descriptor as a way of distinguishing these products, which have different characteristics and are used in distinct recipes. Resorting to this procedure, we have added a descriptor, the adjective flaked, to account for the coarse texture of this ingredient. ${ }^{6}$ Figure 3 highlights the equivalent proposed to render farinha de milho in English.

farinha de milho (noun) flaked cornmeal White or yellow coarse meal obtained from grounding pre-cooked corn and used in the preparation of cuscuz paulista and some kinds of farofa. Ex: Break up the flakes of cormmeal with your hands, forcing it through the sieve. $[B C J]$ Traditionally produced by the native peoples of America, it is in this part of the world where it is more consumed, being essential in the cuisines of Brazil, Colombia, Mexico, Peru and Venezuela Compare with fubá

Figure 3: Entry farinha de milho with proposed translation equivalent

\subsection{Appositive explanation}

Total equivalence is hardly ever achieved when we deal with cultural markers. Adaptations incur loss of the foreignness which characterizes culture-specific items, whereas transference may result in misunderstandings.

Newmark (1988) explains that descriptive equivalents combine description and function, essential elements in explanation and translation. Here, instead of adopting this concept as a translation procedure, we argue that such a strategy can be combined with transference, literal translation, or functional equivalent to provide translators with a definition which combines both description and function.

The type of information included in any definition depends essentially on the purpose of the work of reference. Except for Teixeira and Tagnin (2008), the PortugueseEnglish reference works available do not provide any kind of definition, only translation equivalents. To aid translators and writers, we propose a purpose-specific sentence which

\footnotetext{
${ }^{5}$ See Rebechi (2015a) for a detailed analysis of how dictionaries and glossaries deal with these ingredientes.

${ }^{6}$ See Rebechi (2015a) for a detailed explanation of this translation choice.
} 
allows them to include an elucidation of the cultural term without greatly affecting the fluency of the text. To that end, this appositive explanation consists of a concise phrase, which can either follow the equivalent or be used as a footnote, as a way of providing important information about the term.

The English comparable subcorpus, especially the introductory texts which comprise it, have proved to be excellent sources for the retrieval of relevant information to construct this appositive explanation. Figure 4 shows concordance lines of dendê retrieved from these texts.

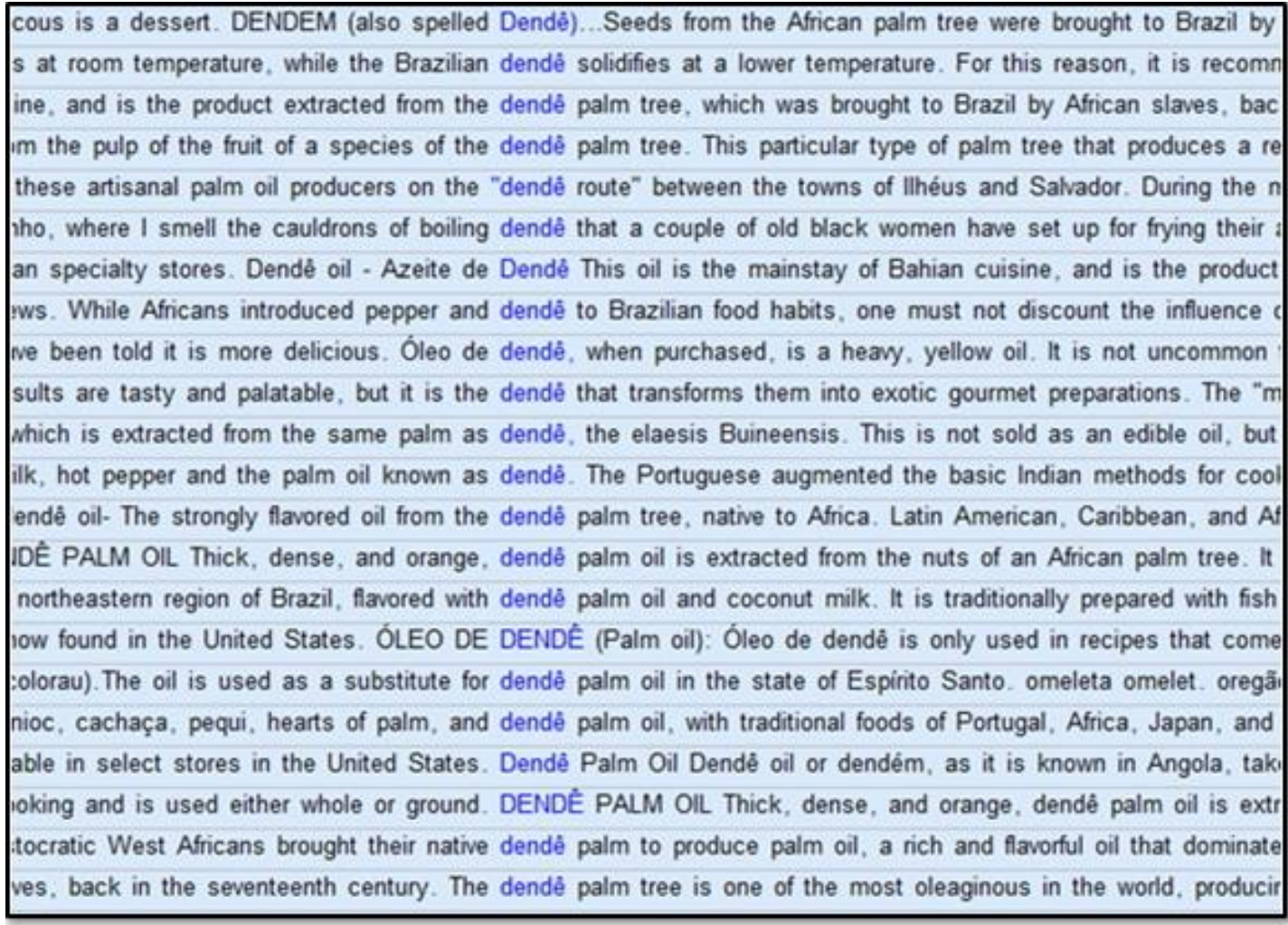

Figure 4: Concordance lines of dendê in introductory texts of cookbooks written in English

As can be seen, the word dendê is used to refer to the tree, to the seeds, and to the oil (azeite de dendê), the latter being used in cooking. Besides, the titles of the recipes which feature dendê also guided us in building the definitions. The concordance lines of dendê showed that it is usually present in Bahian dishes, such as bobó, moqueca, vatapá and acarajé. All this information can be used to build an appositive explanation (see Figure $5)$. 
azeite de dendê (noun) dendê oil, palm oil Thick, dense, reddish oil with a delectable flavor and aroma used as an ingredient of Bahian dishes such as bobó, moqueca and vatapá and also as fat for frying acarajé IEx.: In a medium skallet, heat the remaining dende oil and cook the shrmp with they start to tum orange, about 1 minute per side. [TBK] Ex.: The batter is dropped by spoonfuls into hot palm oil and deep-fat fried. (Braz. Cook.)/l Rich in vitamin A, this oil is extracted from the pulp of the fruit of an African palm tree (Elaesis guineensis) brought to Brazil by slaves in the seventeenth century. Contrary to common belief it is low in cholesterol but high in calories. //Phrase. add the dendê oil; dendê oil, optional; fry in dendê oil; heat the dendê oil Same as dendê See also acarajé, vatapá, moqueca, bobo

Figure 5: Entry azeite de dendê with a highlighted appositive explanation

Because azeite de dendê is a typical Brazilian ingredient, its explanation will privilege texture, color, flavor and culinary uses. When a term may be familiar to other cultures the explanation will highlight its use in the Brazilian cuisine. The explanation for amendoim 'peanut', for example, reads 'seed used roasted in the preparation of savory Bahian dishes such as caruru, vatapá and xinxim, and also in sweet recipes such as pé-de-moleque'.

\subsection{Example}

Again, except for Teixeira and Tagnin (2008), examples are not included in the cooking reference works analyzed. Besides, even when offered (mainly in general language dictionaries), authenticity is not usually sought. However, we believe examples should be authentic, retrieved from naturally occurring texts, thus providing instances of authentic usage of the term, shedding light on the context and even sometimes offering collocations and other phraseological units in which the term may occur. In the Glossary of Brazilian Cooking we offer actual examples retrieved from our corpus. The examples are chosen so as to add further information to enhance the reader's understanding of the term. Figure 6 highlights the examples chosen for the entry azeite de dendê. The examples are given credit by using the initials of the books from which they were extracted. ${ }^{7}$

\footnotetext{
${ }^{7}$ A list with complete references of the books is provided in a separate tab, along with information about the compilation of the glossary.
} 
azeite de dendê (noun) dendê oil, palm oil Thick, dense, reddish oil with a delectable flavor and aroma used as an ingredient of Bahian dishes such as bobó, moqueca and vatapá and also as fat for frying acarajé.//Ex.: In a medium skillet, heat the remaining dendé oil and cook the shrimp until they start to tum orange, about I minute per side. [TBK] EX: The batter is dropped by spoonfuls into hot palm oil and deep-fat fried. (Braz. Cook.// Rich in vitamin A, this oil is extracted from the pulp of the fruit of an African palm tree (Elaesis guineensis) brought to Brazil by slaves in the seventeenth century. Contrary to common belief it is low in cholesterol but high in calories. //Phrase. add the dendê oil; dendê oil, optional; fry in dendê oil; heat the dendê oil Same as dendê See also acarajé, vatapá, moqueca, bobó

Figure 6: Entry azeite de dendê with examples highlighted

\subsection{Encyclopedic information}

Occasionally the appositive explanation may not be sufficient for a broad understanding of the term in its cooking context. The feature 'encyclopedic information' aims at giving the reader extra information about the term, but strictly related to its use in cooking. For example, in the entry azeite de dendê, it is important to provide basic nutritional data, such as the fact that the ingredient is rich in vitamin A, and high in calories but not in cholesterol, as many believe. In some cases, we include historical information and links to other reference sources and even to recipes. Figure 7 highlights this element in the entry azeite de dendê.

azeite de dendê (noun) dendê oil, palm oil Thick, dense, reddish oil with a delectable flavor and aroma used as an ingredient of Bahian dishes such as bobó, moqueca and vatapá and also as fat for frying acarajé.//Ex.: In a medium skillet, heat the remaining dende oil and cook the shrimp until they start to turn orange, about 1 minute per side. [TBK] Ex.: The batter is dropped by spoonfuls into hot palm oil and deep-fat fried. (Braz. Cook.)/l/ Rich in vitamin A, this oil is extracted from the pulp of the fruit of an African palm tree (Elaesis guineensis) brought to Brazil by slaves in the seventeenth century. Contrary to common belief it is low in cholesterol but hiah in calories //Phrase. add the dendê oil; dendê oil, optional; fry in dendê oil; heat the dendê oil Same as dendê See also acarajé, vatapá, moqueca, bobó

Figure 7: Encyclopedic information for the entry azeite de dendê

\subsection{Phraseological units}

Recent developments in the field of terminology have led to a growing interest in phraseology, since in general translators and specialized writers need to use the terms in 
context, not in isolation, to produce fluent texts in the target language. The frequent cooccurrence of words is known by various names: n-grams, multi-word units, clusters, and lexical bundles are some, but not all refer to co-occurrences that convey complete meanings. WordSmith Tools generates clusters, which are patterned combinations of words, but not necessarily complete units of meaning. For example, a frequently occurring combination of words such as devein and is not understood as complete, but shell, devein and wash shrimp is.

Access to specialized phraseological units enables translators to write fluent texts in any given domain, since equivalence is not the only difficulty involved in the translation of cultural markers. Let us take the term cebola as an example. A translator would hardly have any difficulty in rendering it as onion in the English text. Nevertheless, when faced with the phraseology cebola cortada em quatro, the professional, if tempted to use a literal translation strategy, would produce a phrase such as onion cut in four, which is not a recurring combination in English. A quantitative analysis will provide us with patterns such as onion, quartered; onion, diced; onion, finely chopped, etc., from which the translator can select the most suitable one (onion, quartered in this case).

In addition to the fields mentioned, the Glossary of Brazilian Cooking also features cross-references to indicate the semantic-conceptual relations between terminological units. For example, in the entry for camarão, a reference such as "Compare with pitu" helps to distinguish the term camarão 'shrimp' with a type of freshwater shrimp, whereas the reference "See also abará, acarajé, etc." will refer the reader to dishes in which the term is a key ingredient.

Images may also be helpful in clarifying the meaning of cultural markers. Therefore, this aid has been included whenever deemed relevant. Figure 8 shows a complete entry, using the term camarão as an illustration. 


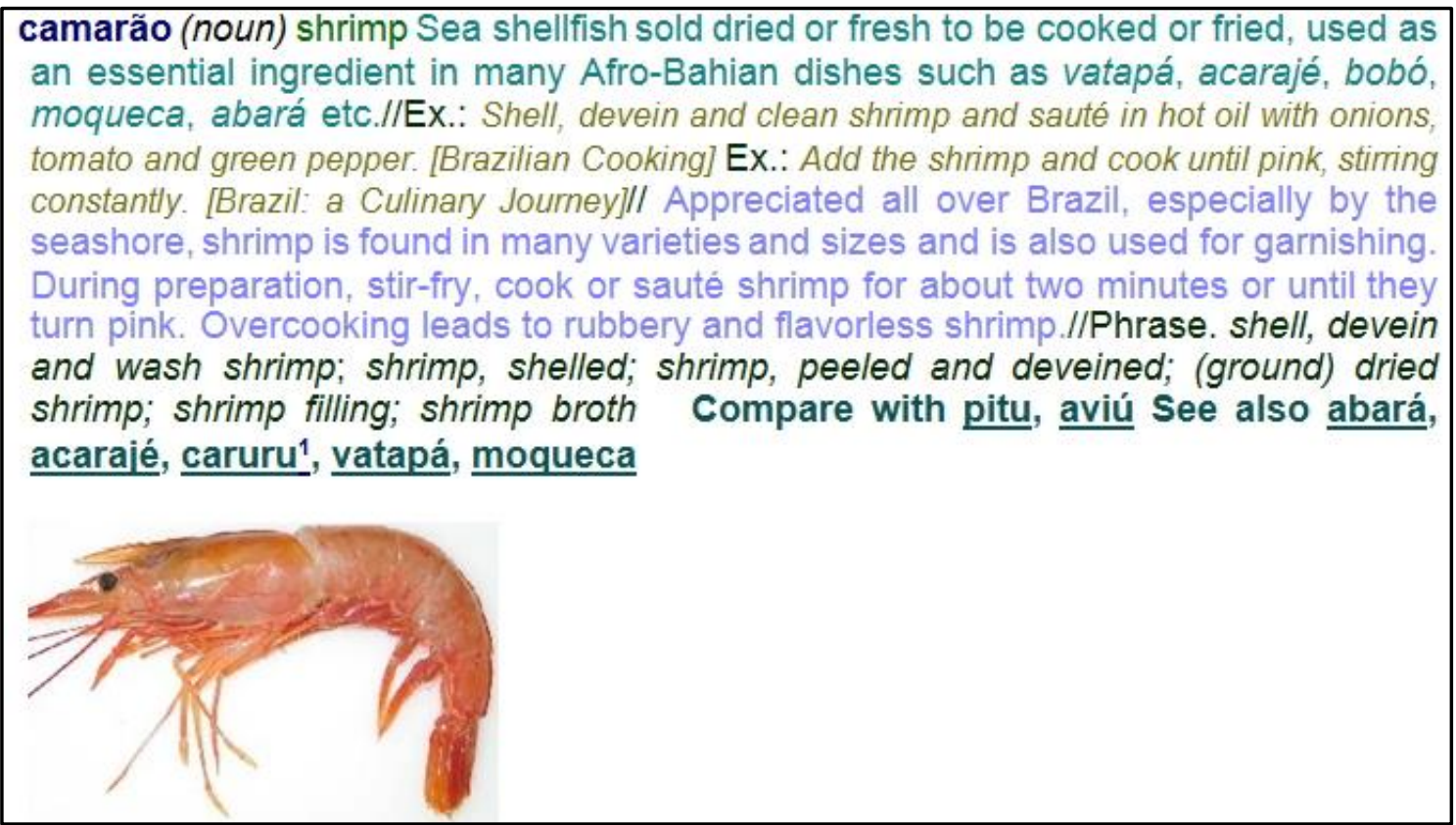

Figure 8: Complete entry of the Portuguese-English Glossary of Brazilian Cooking for camarão

\section{CONCLUDING REMARKS}

Given that texts about Brazilian cuisine, written in or translated into English, often suffer from misleading or distorting lexical choices when it comes to ethnic food terms, and assuming these issues could be minimized if professionals had access to more comprehensive and reliable terminological resources, this paper proposes the compilation of a Portuguese-English Glossary of Brazilian Cooking aimed at translators and specialized writers. To accomplish our aims, we have relied on a CL approach.

In addition to appropriate equivalents, we propose a few features aimed at facilitating the translation of cultural terms. The main one, which represents an innovation in Brazilian culinary reference materials, is an appositive explanation, a short text which can be inserted in the translation without affecting its fluency or, if the writer so chooses, used as a footnote. Next, authentic examples taken from our corpora are provided. In addition, we offer extra information for the term, in case the translator or reader is interested in learning more about it. Therefore, we propose the inclusion of encyclopedic information, which may give historical details of the ingredient or dish, add a recipe or links to other reference sources. Phraseology is also addressed showing the appropriate use of a term in relation to its most frequently occurring collocates so as to add fluency to the text. 
We believe that a carefully compiled reference source with cultural information would help not only to prevent mistakes but also to recover cultural markers in the target text, whether predominantly literary or specialized. Besides, we hope that our proposal for a three-level entry in a specialized glossary will find application in other terminological areas, especially those focused on the compilation of reference works which address cultural items.

\section{REFERENCES}

Amado, Jorge. 1966. Dona Flor e seus Dois Maridos. São Paulo: Companhia das Letras. Azenha Jr., João. 1999. Tradução Técnica e Condicionantes Culturais: Primeiros Passos para um Estudo Integrado. São Paulo: Humanitas.

Barnes, Julian. 2003. The Pedant in the Kitchen. London: Atlantic Books.

Bowker, Lynne and Jennifer Pearson. 2002. Working with Specialized Language: A Practical Guide to Using Corpus. London: Routledge.

Brien, Donna L. 2007. Writing about food: Significance, opportunities and professional identities. In Jen Webb and Jordan Williams eds. Proceedings of the $12^{\text {th }}$ Annual Conference of the Australian Association of Writing Programs. Canberra: University of Canberra, 1-15.

Bubel, Claudia and Alice Spitz. 2013. The way to intercultural learning is through the stomach. In Cornelia Gerhardt, Maximiliane Frobenius and Susanne Ley eds. Culinary Linguistics: The Chef's Special. Amsterdam: John Benjamins, 157-187.

Capatti, Alberto and Massimo Montanari. 1999. La Cucina Italiana: Storia di una Cultura. Roma-Bari: Editori Laterza.

Carli, Francesco and Eliane Klotz eds. 2007. Dicionário Gastronômico: PortuguêsEspanhol-Inglês-Alemão-Francês-Italiano. São Paulo: Contorno.

Chesterman, Andrew. 1997. Memes of Translation: The Spread of Ideas in Translation Theory. Amsterdam: John Benjamins.

Cotter, Colleen. 1997. Claiming a piece of the pie: How the language of recipes defines community. In Anne L. Bower ed. Recipes for Reading: Community Cookbooks, Stories, Histories. Massachusetts: University of Massachusetts Press, 51-72.

Dubuc, Robert. 1999. Manual Práctico de Terminología (translated by Ileana Cabrera). Providencia: RiL.

Gerhardt, Cornelia. 2013. Food and language -language and food. In Cornelia Gerhardt, Maximiliane Frobenius and Susanne Ley eds. Culinary Linguistics: The Chef's Special. Amsterdam: John Benjamins, 3-49.

Gerhardt, Cornelia, Maximiliane Frobenius and Susanne Ley eds. 2013. Culinary Linguistics: The Chef's Special. Amsterdam: John Benjamins.

Instituto Americano de Culinária. 2011. Chef Profissional (fourth edition). São Paulo: Senac.

Joffe, David and Gilles-Maurice de Schryver. 2004. TshwaneLex, a state-of-the-art dictionary compilation program. In Geoffrey Williams and Sandra Vessier eds. Proceedings of the Eleventh EURALEX International Congress. Lorient Cedex: Université de Bretagne Sud, 99-104.

Jurafsky, Dan. 2014. The Language of Food: A Linguist Reads the Menu. New York: W. W. Norton \& Company. 
Klie, Virginia. 2006. Glossário de Gastronomia: Português-Inglês / Inglês-Português. Rio de Janeiro: Disal.

Labov, William. 1972. Language in the Inner City: Studies in the Black English Vernacular. Philadelphia: University of Pennsylvania Press.

Mayoral Asensio, Roberto M. 2007. Specialised translation: A concept in need of revision. Babel: Revue Internationale de la Traduction 53: 48-55.

McEnery, Tony and Andrew Hardie. 2012. Corpus Linguistics: Method, Theory and Practice. Cambridge: Cambridge University Press.

Ministério da Cultura. 2014. Aromas, Cores e Sabores do Brasil. http://www.copa2014.gov.br/sites/default/files/livreto_web17062013.pdf (1 April, 2020.)

Newmark, Peter. 1988. A Textbook of Translation. New York: Prentice-Hall.

Nord, Christiane. 2001. Translating as a Purposeful Activity: Functionalist Approaches Explained. Manchester: St Jerome.

Nord, Christiane. 2012. Functional approaches to translation. In Carol A. Chapelle ed. The Encyclopedia of Applied Linguistics. Hoboken: Blackwell Publishing, 22232228.

Pearson, Jennifer. 1998. Terms in Context. Amsterdam: John Benjamins.

Rebechi, Rozane R. 2012. 'Cachaça' na tradução de obras literárias brasileiras para a língua inglesa. Tradterm 20: 95-110.

Rebechi, Rozane R. 2015a. Tracing English equivalents of Brazilian Portuguese cooking vocabulary: A corpus-based study. In Sattar Izwaini ed. Papers in Translation Studies. Newcastle upon Tyne: Cambridge Scholars, 154-178.

Rebechi, Rozane R. 2015b. A Tradução da Culinária Típica Brasileira para o Inglês: Um Estudo sob o Enfoque da Linguística de Corpus. São Paulo, SP: The University of São Paulo dissertation.

Saldanha, Roberta M. 2015. Dicionário de Termos Gastronômicos em 6 Idiomas. Rio de Janeiro: Senac.

Scott, Mike. 2012. Wordsmith Tools Version 6.0. Stroud: Lexical Analysis Software.

Scott, Mike and Christopher Tribble. 2006. Textual Patterns: Key Words and Corpus Analysis in Language Education. Amsterdam: John Benjamins.

Teixeira, Elisa D. 2004. Receita Qualquer um Traduz. Será? A Culinária como Área Técnica de Tradução. São Paulo, SP: The University of São Paulo dissertation.

Teixeira, Elisa D. 2008. A Linguística de Corpus a Serviço do Tradutor: Proposta de um Dicionário de Culinária Voltado para a Produção Textual. São Paulo: The University of São Paulo dissertation.

Teixeira, Elisa D., and Stella E. O. Tagnin. 2008. Vocabulário para Culinária: InglêsPortuguês. São Paulo: SBS.

Temmerman, Rita and Danièle Dubois eds. 2017. Food and terminology: Expressing sensory experience in several languages. Special issue of Terminology 23/1.

Tigner, Amy L. and Allison Carruth. 2018. Literature and Food Studies. London: Routledge.

Webster's Portuguese-English Dictionary (eighteenth edition). 2007. Rio de Janeiro: Record.

Zavaglia, Adriana, João Azenha and Tinka Reichmann. 2011. Cultural markers in LSP translation. In Klaus-Dieter Baumann ed. Fach - Translat - Kultur: Interdisziplinäre Aspekte der Vernetzten Vielfalt. Berlin: Frank und Timme, 785808. 
Corresponding author

Rozane Rebechi

Avenida Bento

Gonçalves, 9500,

Porto Alegre, RS, Brazil

e-mail: rozane.rebechi@ufrgs.br

received: January 2020

accepted: April 2020 